\title{
TÜRKÇEDE BİR SÖZCÜK TÜRÜ VE SÖZCÜK TÜRETME YOLU OLARAK KARMA SÖZCÜKLER ${ }^{1}$
}

Mehmet Vefa NALBANT ${ }^{2}$

\begin{abstract}
Özet
Dillerin incelenmesinde ölçüt olarak kabul edilen yapısal özellikleri, birbiriyle aynı veya farklı dillerin çeşitli aileler oluşturmalarına olanak sağlamaktadır. Ortak yönler üzerinde kurulmuş bu ailelerdeki dillerin ara sıra aynı dil ailesinden olmayan dillerle de bazı yapısal benzerlikler gösterdikleri görülebilmektedir. Bu çalışmamızda Türkçenin ölçünlülüğü dışında kalan bir sözcük türetme yolu ve bu yolu kullanan başka dillerle Türkçenin ilişkisi ortaya konmaya çalışılacaktır. Diğer yandan Hint-Avrupa dilleri için bile yeni bir yol olarak kabul edilen karma sözcük türetme şeklinin Türkçe için eskiliğine de bu incelemenin sınırları içinde dikkat çekilecektir.
\end{abstract}

Anahtar Kelimeler: Kelime Türetme, Karma Sözcükler, Türkçede Karma Sözcükler, Dil İlişkileri.

\section{BLENDING WORDS AS A WORD TYPE AND WORD DERIVATIAON WAY IN TURKISH}

\begin{abstract}
Identical structural features are considered as the criteria for the study of languages and allows to create several families for different languages. Some of the languages of the same language family occasionally show some structural similarities with non-family languages.

In this paper, mixed Turkic word formation methods and relationship with other languages using this route will be revealed. This way, even for Indo-European languages are considered as a new way. Turkish.

On the other hand, In this paper will be attend to ancientness of blending word in

Key Words: Word Derivation, Blending Words, Blending Words İn Turkish, Language Relations.

\section{Giriş}

Dillerin tarihsel kökenlerinin belirlenmesinde ve bir aile oluşturulmalarında ölçüt olarak kullanılan yapısal özellikleri ve sözcük türetme yolları, dillere ilişkin genelleşmiş bazı ölçünlüklerin oluşmasına imkân sağlamıştır. Bu ölçünlükler sayesinde dillerin akrabalıkları, benzerlikleri veya farklılıklarını belirlemek çok daha kolay olmaktadır. Bununla birlikte her dil için kendisiyle akraba olmayan dillerle uygunluk gösterebilecek ve ölçünlülüklerin dışına çıkan yapısal sıra dışılıklar görülebilir. Bu durum daha evrensel dil akrabalıklarının araştırılmasına imkân vermenin ve bu yoldaki araştırmaların doğruluğunun kanıtı olarak gösterilebileceği gibi, söz konusu dilin bir sıra dış1lı̆g 1 olarak görülüp sadece bu çerçeveden bakılarak da inceleme konusu yapılabilir.
\end{abstract}

Türkçenin tarihsel gelişim aşamalarına bakıldığında kendine akraba kabul edilen diller gibi yapı bakımından eklemeli olduğu ve sözcük türetmede de kök ve/veya gövdeye getirilen

\footnotetext{
${ }^{1}$ Bu makale 19-22 Aralık 2012 tarihleri arasında Denizli'de düzenlenen 5. Uluslararası Dünya Dili Türkçe Sempozyumunda sunulan ve aynı adı taşıyan bildiriden genişletilerek hazırlanmıştır.

${ }^{2}$ Prof. Dr., Pamukkale Üniversitesi, el-mek: vnalbant@gmail.com
} 
eklerden yararlandığ 1 görülür. Bu, Türkçenin sözcük türetme konusunda bilinen ve en sık başvurduğu yol olmakla birlikte, bu konuda kullandığ tek yol değildir. Daha önce kaleme aldığımız bir makalede Türkçenin "almaşma (alternation)" yoluyla sözcük türetme olanaklarına sahip olduğunu göstermeye çalışmıştık (Nalbant 2008: 17-56).

$\mathrm{Bu}$ çalışmamızda özellikle Hint-Avrupa dillerinin ve bu arada Japonca gibi Altay dillerinin sözcük türetme konusunda özellikle son dönemlerde başvurduğu bir yol olan karma sözcük yapılarını ve bu şekilde oluşmuş Türkçe sözcükleri ele alarak, bu tip yapılar aracılığıyla Türkçenin sözcük türetme olanaklarını ve bu olanakların işletilme tarihini ve süreçlerini değerlendirmeye ve bu konuda bazı öneriler sunmaya çalışacağız.

\section{Karma Sözcükler ve Karma Sözcük Yapıları}

Dilbilimsel karışma iki veya daha fazla parçanın karışımı demektir ki, bu parçalar bazen morfemdir. Dilbiliminde bu tip sözcük türetme yolu blends, blendings, portmanteau words, telescopy gibi terimlerle adlandırılmaktadır.

Karıştırma iki girdi alanından ayrı alanlarda bir yapı karışımı olarak öngörülmektedir. Girdi alanlarından alınan kısmi bir miras ile karışma yeni bir yapı olarak ortaya çıkar (Fauconnier, Turner 1996). Karışma iki veya daha fazla sözcük kökünden birleştirmelerle yeni bir sözcük oluşturma yoludur (Gries 2004:1).

Karma sözcüklerin dilin en az çaba yasasının bir gereği olarak da ortaya çıktığı düşünülmektedir. Özellikle İngilizcede son on yıl içinde bu tip sözcük oranının neredeyse iki kat arttığ1 görülmektedir (Bakaradze 2010:86). Bu sözcük türetme yolu diller için yeni olarak değerlendirilmekle birlikte özellikle batı dillerini araştırma konusu yapmış bazı dil bilimciler bunun çok erken devirlerden beri kullanıldığını ileri sürerek kendi araştırma dillerine ilişkin örnekler göstermeye çalışmaktadırlar (Bakaradze 2010:88)

\subsection{Karma Sözcük Tipleri}

Karma sözcükler üzerine yapılan çalışmalar sonucunda bunların oluşmasında üç temel yol kullanıldığı ortaya konmuştur (Algeo 1977). Bu yöntemlerle oluşan yeni sözcüğün anlamı, tamamen veya kısmen oluştuğu sözcüklerin anlamı ile ilgili olur(Bakaredze 2010:87). Karma sözcük oluşmasına ilişkin üç temel tip bilinmektedir:

a. Fonemik binişme (Phonemic Overlap) : Bir hece veya bir hecenin bir kısmı iki sözcük arasında paylaşılır. gelmesi.

b. Kırpma (Clipping) : İki sözcüğün kısalması ve son kısalan şekillerin bir araya

c. Fonetik Binişme ve Kırpma (Phonemic Overlap and Clipping): Aynı heceyi almak için kısalan iki sözcüğün bir araya gelmesi (Algeo 1977).

Bu seslik olaylar sonucunda oluşan sözcüklerin ilkinde veya ikincisinde, çoğu zaman da her ikisinde yeni sözcüğün oluşması için bazı değişiklikler oluşmaktadır:

a. İlk sözcüğün başı ikinci sözcüğün sonu bir araya getirilir:

$$
\text { breakfast }+ \text { lunch=brunch }
$$

b. Her iki sözcüğün başı yeni sözcüğün oluşturulması için bir araya getirilir:

$$
\text { cybernetic (sibernetik) + organism }(\operatorname{organizma})=\text { cyborg }
$$



getirilir:

c. İki sözcügün sesleri yeni sözcüğü oluşturmak için ortak sesler etrafinda bir araya

$$
\begin{aligned}
& \text { California }+\quad \text { fornication }(\text { evlilik } \quad \text { dış1 } \quad \text { ilişsi }) \quad=\text { Californication, } \\
& \text { motor }(\text { motor })+\text { hotel }(\text { otel })=\text { motel }
\end{aligned}
$$

d. İki birleşik sözcügün birçok sesi sıralarını çoğunlukla koruyarak yeni bir sözcük oluşturmak için karma bir hale gelir:
$\underline{\text { lithe }}$ (kıvrak) +slimy
(sümüksü) $=$
(http://en.wikipedia.org/wiki/Blend:20.10.2012)
slithy

\section{Türkçede Karma Sözcükler}

Türkçe bilinen sözcük türetme yolları dışında başka yollara çok sık başvurmasa da, bu durum ekler dişında başka bir sözcük türetme yolu yoktur anlamına gelmemektedir. Aslında Chomsky tarafından ileri sürülen evrensel dilbilgisi teorisi de bütün dillerin aynı temel olanaklara sahip olduğundan hareket etmektedir. $\mathrm{Bu}$ bakış açısıyla sözcük türetimi söz konusu olduğunda herhangi bir dilin sahip olduğu olanaklardan başka dillerin mahrum olduğunu düşünmek dilin yapısına da aykırı kalmaktadır. Fakat her dilin daha çok kullandığı olanakları vardır ve bu olanaklardan bir veya birkaçına daha işlerlik kazandırmıştır. Türkçe de eklerle sözcük türetme imkânlarını daha çok işletmişken başka sözcük üretme yollarına bu firsatı çok vermemiştir. Bununla birlikte almaşma da dâhil olmak üzere Türkçe batı dilleri için eskiliği de bir tartışma konusu olan karıştırma yoluyla karma sözcükler oluşturmayı da bir yöntem olarak kullanmak yoluna gitmiştir.

Yaptığımız araştırmalarda Türkçede şimdiye kadar dil bilimsel anlamda Blend word terimine karşılık gelecek şekilde karma sözcüklere ilişkin bir çalışmaya rastlanmamıştır. Bir çalışmada karma sözcükler ele alınmışsa da bu çalışmada bu terimle kastedilen; Türkçe-Arapça, Arapça-Türkçe, Farsça-Türkçe, Türkçe-Farsça gibi iki dilin sözcüklerinin bir arada kullanılmasıyla oluşturulmuş yeni sözcükler olmuştur (Gözütok: 2008).

$\mathrm{Bu}$ çalışma dışında bazı köken bilgisi araştırmalarında, Türkçenin yazımı konusunda yeni bazı eğilimlerinin saptanmasına ilişkin çalışmalarda ya da Türkçenin batı dilleriyle ilişkisi söz konusu edildiğinde (Sarı 2008) bazı sözcüklerle ilgili değinmelere rastlanılmıştır.

Bizim çalışmamızda, bu konu en azından bizim ulaşabildiğimiz kaynaklarla ilk kez Türkçe bakımından söz konu edilecektir. Bu çerçevede rastgele bir taramayla saptanan ve karma sözcük olduğuna inandığımız Türkçe sözcükler değerlendirilecektir. $\mathrm{Bu}$ sözcüklerin karma sözcükler bakımından oluşma yöntemlerine ve bu arada kökenlerinin araştırılmasına girmeden önce bizim hangi sözcüklerin karma sözcük olarak değerlendirilebileceğine ilişkin olarak belirlediğimiz ölçütleri sıralamamız gerekmektedir. Buna göre bir sözcüğün Türkçede karma sözcük olarak kabul edilebilmesi için şu ölçütleri taşıması gerekmektedir:

a. Kısalma, yıpranma vb. nedenlerle yan yana gelmiş iki sözcükten oluşmalı ve bir araya gelmiş sözcükler ekli bir tamlamadan oluşmamalıdır.

b. Yeni oluşan sözcüğün anlamı, kısaldığı sözcüklerin anlamıyla ilişki taşımasına rağmen yeni bir anlamla ortaya çıkmalıdır. 
c. Bu yeni sözcük sözlükte madde başı olmalıdır.

$\mathrm{Bu}$ ölçütler 1şı̆̆ında aşağıda oluşma durumlarına göre saptadığımız Türkçe karma sözcükler incelenmiştir:

\subsection{Karma Sözcük Yapılarıyla Oluşmuş Akrabalık Adları}

\subsubsection{Kırpma Sonucu Olușmuș Akrabalık Adları}

$\mathrm{Bu}$ yolla oluşmuş Türkçe üç akrabalık adı bulunmaktadır. Bu sözcüklerden ikisinde ilk sözcüğün tümü korunmuş, ikinci sözcügün başındaki ses ise düşmüştür. Bir sözcükte ise birinci sözcüğün son ünlüsü ile ikinci sözcüğün ilk ünlüsü düşmüş ve kısalan iki sözcük bir araya gelerek yeni bir sözcük oluşturmuştur. Bu şekilde oluşmuş akrabalık adları şunlardır:

\subsubsection{1. İlk Sözcügüun Tümü+İkinci Sözcüğün Son Hecesinin Bir Araya Gelmesi İle} Oluşanlar

\subsection{Teyze}

Tarihi Uygur (U III 33,17; U II 80,67) ve Karahanlı Türkçesi metinlerinde (DLT III, 238) tagāy "dayl” olarak tespit edilen ve Teyze sözcügünün birinci kısmını oluşturan sözcüğe ek olarak, Bulgar Türkçesi metinlerinde tagza "teyze" şeklinin de varlığı saptanabilmektedir (Clauson 1972:474).

Sözcüğün tāy-agas, tay-eze, dayl-apa, tay-eze, tay-yene, tay-eye, dāy-ava, teynek>tayl ene (Räsänen 1969:455-456) gibi Türk lehçelerinde ikinci sözcüğü birbirinden farklı sözcüklerle bir araya getirilmiş örneklerine rastlamak mümkündür. Burada dikkat çeken nokta sözcükleri oluşturan tay kısmının aynı kalmakla birlikte ikinci kısmın farklı akrabalık adlarından meydana getirilmiş olmasıdır.

Doerfer day sözcügünü incelerken Türkçede bu sözcüğün tagai ve tayı olmak üzere iki şeklinin olduğuna dikkat çeker ve sözcügün tayai şeklinin bazen sondaki $i$ küçültme ekini kaybettiğine ilişkin bilgiyi aktarır. Tayï sözcügünü de tai +iyelik eki+ tekrar beliren $\ddot{i}$ şeklinde açıklar (Doerfer 1967:196/1176).

Tekin (1960:291) ise, sözcügün ağızlardaki ve bazı Türk lehçelerindeki farklı şekillerini gösterdikten sonra, sözcüğün Osmanlıca sözlüklerde تيز imlasında kaydedilmesinden ve XVII. yüzyılda Roma'da basılmış olan bir İtalyanca-Türkçe sözlükte de sözcüğün aynı imla ile yazılmış olmasından hareketle teyze söyleyişinin epeyce eski olduğunu ifade eder. Tekin'e göre sözcük tagay ve eze sözcüklerinden oluşmuştur:

Tagāy $>$ tay + eze $>$ tayze $>$ teyze (Tekin 1960:293)

\subsection{Abaga}

Kabilenin en yaşlısı, babanın büyük kardeşi anlamına gelen ve Yakutçada abaga, Kumancada ise abagay olarak kullanılan bu sözcüğü Talat Tekin $a p a>a b a+a g a$ sözcüklerinden oluşmuş sayar (Tekin 1960:289) 


\section{İle Oluşanlar \\ 2.1.1.2 İlk Sözcüğün İlk Hecesi+İkinci Sözcüğün Son Hecesinin Bir Araya Gelmesi}

\subsubsection{1 Amca}

İki sözcüğün kırpılması sonucu oluşmuş karma bir akrabalık adıdır. Bu sözcük köken bakımından Arapça 'amm "amca" sözcüğüyle karışmasına rağmen, Türkçe apa+eçe sözcüklerinden oluştuğu ortaya konmuştur. Talat Tekin'in ileri sürüdüğü köken bilgisi denemesi, Tietze (2002), Räsänen (1969), Yong Song Li (1999) tarafından da kabul edilmiştir.

Talat Tekin'e göre bu sözcük: 291).

apa eçe $>$ apaçe $>$ abuce $>$ amuca $>$ amca gelişimini göstermiştir (Tekin 1960:283-

\subsection{Karma Sözcük Yapılarıyla Oluşmuş Nesne Adları}

\subsubsection{Kırpma Sonucu Oluşmuş Nesne Adları}

İncelememize konu olan ve kırpma yoluyla oluşmuş bir nesne adımız bulunmaktadır. $\mathrm{Bu}$ sözcüğün kökeni ile ilgili farklı görüşler bulunmakla birlikte sözcüğün bazı Türk lehçelerinde korunan biçimleri karma bir sözcük olduğu düşüncesini güçlendirmektedir. Oluşanlar

2.2.1.1 İlk Sözcüğün Başı+İkinci Sözcüğün Sonunun Bir Araya Gelmesi İle

\subsection{Bilezik}

Eski Türkçe metinlerde bilezök veya bilersök, DLT'de bilezük, Çağatay Türkçesi metinlerinde bilerzik olarak saptanabilen sözcük, Talat Tekin'e göre bile- "beli veya bileği sarmak" + sük ekinden oluşmuş bir sözcüktür (Tekin 2003:31).

Marcel Erdal da bilezük ve bilersük sözcüklerinde görülen bilek ve biler sözcüklerini *bile- veya *bele- "kavramak" sözcüklerinden geliştiğini düşünür (Erdal 1991:I-158).

Bilezik sözcüğünün Yeni Uygur ve Özbek Türkçelerindeki bilek üzük ve bilegüzük biçimlerinden hareket eden Gülensoy ise bilezik sözcüğünü bilek+yüzük olarak inceler (Gülensoy 2007:146)

Biz de Gülensoy'un Özbek ve Yeni Uygur Türkçelerindeki sözcüğün var olan biçimlerinden hareketle yapmış olduğu açıklamayı kabul ediyor ve sözcügün kırpma neticesinde Türkçenin bazı tarihi ve çağdaş lehçelerinde bilezük şekline gelişerek ortaya çıktığını düşünüyoruz:

$$
\text { Bile-k+yüzük }>\text { bilekyüzük }>\text { bileküzük }>\text { bilekzük }>\text { bilezük }
$$

\subsection{Karma Sözcük Yapılarıyla Oluşmuş Mekân Adları}

\subsubsection{Fonetik Binişme ve Kırpma Sonucu Oluşmuş Mekân Adları}

\subsubsection{Birinci Sözcüğün Başı İle İkinci Sözcüğün Sonunun Bir Araya Gelmesi ve} Benzer Hecenin Paylaşılması İle Oluşan Mekân Adları

\subsection{Kaplica}

"Ilıca"(Türkçe Sözlük 2005:1071), "Yerden tabii olarak çıkan sıcak su üzerine yapılmış hamam, kaynarca, 1lıca" (Ayverdi 2011:1584) olarak tanımlanan kaplıca sözcüğü üzeri kaplı olması ile 1lıcadan ayrılmaktadır. Azeri Türkçesine ilişkin hazırlanmış bir sözlükte "Üstü kapalı kümbetli 1lıcaya kaplıca denilir, üstü olan 1lıcaya ise kaynarca denilir” (Hadi 2010:6305), şeklindeki açıklamayla 1lıca, kaplıca ve kaynarca terimlerinin farkı ortaya konmaya çalışılır. 
Sözcügünün kökenini araştıran Gülensoy hazırladığı etimolojik sözlüğünde kaplıca sözcüğünü kap sözcüğünden gelişmiş ve eklerle genişlemiş kapllgçak sözcüğüne götürür ve eklerdeki son seslerin yitimi ile sözcüğün kaplıca şekline geliştiğini ileri sürer:

Kap $+l \dot{g}+$ çak $>$ kaplıca (Gülensoy 2007:461)

Eren ise, Türkçede yaygın olarak kullanılan kaplıca biçiminin haploloji sonucunda oluştuğunu ifade eder ve sözcügün gelişimini kaplı+1lıca şekline götürerek gelişimini şöyle açıklar:

Kaplı llıca $>$ kaplilıca $>$ kaplica $($ Eren 1999:209)

Eren'in açıklamalarından da anlaşılabileceği gibi kaplıca terimi iki sözcükten oluşmuş ve kırpma ve fonetik binişme sonucu son şeklini almıştır.

\subsection{Karma Sözcük Yapılarıyla Oluşmuş İçecek Adları}

\subsubsection{Kırpma sonucu Oluşmuş İçecek Adları} Oluşanlar

2.4.1.1. İlk Sözcüğün Başı+İkinci Sözcüğün Sonunun Bir Araya Gelmesi İle

\subsubsection{Kımran}

$\mathrm{Bu}$ çalışmanın oluşmasına neden olan sözcüktür. Kazakistan'daki bir sempozyumda bulunduğum sırada bize Kımran sunulması sonucunda oradaki tarihçi akademisyenlerin sözcüğün kökeni ile ilgili sorduğu soruya benim kımranın tadından hareketle bir anda kımız+ayran sözcüklerinden oluşmuş gibi görünüyor şeklindeki cevabıma daha sonra eklenen düşünceler ve bu tip sözcüklerin araştırılması ile bu çalışmamız ortaya çıkmıştır. Bu sözcüğün kökeni ile ilgili olarak taradığımız sözlüklerde bir bilgi bulunmamaktadır. Fakat Yudahin sözlüğünde kımıranın yapılışı hakkında verilen bilgi ile yine bir internet sitesinden aldığımız bilgi kımranın yapılışında süt ve su veya deve sütü, kısrak sütü karışımı olduğu yolunda bazı bilgiler vermektedir ki, bu bilgiler içeceğin kımız ile ayran arasında olduğunu göstermektedir ki, bu durum içeceğe ad verilmesinde etki etmiş olmalıdır.

Kım(1)ran: Su katıştırılan süt veya yoğurt.(Yudahin 194:II-454)

Kımran : Kımız deve sütünden de yapılır. Ancak deve sütüne kısrak sütü karıştırılması gerekir; deve ve kısrak sütlerini karıştırmak suretiyle elde edilen kımıza Kımran ya da Kumran denir. Kımızın çeşitleri vardır. Kıpçaklarda başlıca üç çeşit kımız bulunur (http://www.turkish-cuisine.org/pages.php?ParentID=5\&FirstLevel=71, İçki Sofras1 Süleyman Kazmaz,16.10. 2012)

Bu bilgiler 1şığında sözcüğün şu şekilde oluştuğu varsayılmıştır:

Kımız +ayran > kımran

\subsection{Karma Sözcük Yapılarıyla Oluşmuş Durum Adları}

\subsubsection{Kırpma Sonucu Oluşmuş Durum Adları} Oluşanlar

2.5.1.1. İlk Sözcüğün Başı+İkinci Sözcüğün Sonunun Bir Araya Gelmesi İle

\subsection{Gerzek}

Türkçe Sözlük'te(2005:754) “geri zekâlı” anlamına gelen argo bir sözcük olduğu belirtilmiş, sözcügün oluşumu konusunda ise bir bilgiye yer verilmemiştir. 
Tietze'nin etimolojik sözlüğünde ise sözcüğün "aptal, salak" anlamına geldiği ifade edildikten sonra Hulki Aktunç’un sözlüğüne gönderme yapılmıştır ( Tieitze 2009: II-137)

Hulki Aktunç'un yukarıda adı geçen argo sözlüğünde sözcüğün anlamı yanında oluşma biçimi de gösterilmiştir. Buna göre gerzek sözcügü geri zekâl1 sözcügüüün argodaki kısaltmasından oluşan bir tabirdir (Aktunç 1990:113).

Geri+zekal1 > gerzek

\subsection{Karma Sözcük Yapılarıyla Oluşmuş Terim Adları}

\subsubsection{Fonemik Binişme ve Kırpma Sonucu Oluşmuş Terim Adları}

\subsubsection{1. İlk Sözcüğün İlk Üç Sesi +İkinci Sözcükle Ortak Olan Ses+ Ortak Sesle Birilikte Tamamlanmış İkinci Sözcük}

\subsection{Avrasya}

Batılı dilerde yapılmış bir karma sözcük olup, İngilizcede eurasia, Almancada eurasien, Fransızcada ise eurasie şeklindedir (tdkterim.gov.tr/bts/, 12.10.2012).

Sözcük Avrupa + Asya sözcüklerinin Türkçede söyleniş şekilleri etrafında fakat Batılı şekil örnek alınarak yapılmıştır. Diğer sözcüklerden bağımsız olarak Türkçede alıntı yoluyla oluşmuş yeni bir karma sözcüktür. Bu nedenle Türkçenin karma sözcük yapılarının Türkçede tarihi dönemlerden başlamak üzere kullanıldığına ilişkin bir sözcük olarak değerlendirilemez. Çalışmamızda Türkçede yer alan ve taramamıza takılmış bir sözcük olduğundan burada yer verilmiş̧tir.

Euro+Asie $>$ Avrup+a+sya $>$ Avrasya

\section{Sonuç}

1. Karıştırma yoluyla sözcük oluşturma zihni bir süreçtir ve karışma her iki girdi ile ilgili olan bir çıktı alınmasıyla sonuçlanır.

2. Hint-Avrupa dilleri ile Hami-Sami dillerinin ve son y1llarda Japoncanın da başvurduğu bu sözcük türetme yolunun eskiliği bu dillerin uzmanlarınca tartışılmakta ve yeni olmadığı yönünde bazı yeni fikirler oluşmaktadır. Bununla birlikte günümüzde hala bu sözcük türetme yolunun Avrupa dilleri için yeni bir yol olduğu öngörülmektedir.

3. Türkçe eklerle sözcük yapma yolunu daha çok kullanarak bunu genelleştirmiştir. Bununla birlikte ihtiyaç halinde başka imkânlara da başvurma yoluna gitmiştir. Karma sözcük yapıları bu imkânların işletilmesi ile ortaya çıkmıştır.

4. Çalışmamızda karma sözcük yapıları değerlendirilirken her iki sözcügü de eksiz olan karma sözcüklerin seçilmesine özen gösterilmiştir. Bu nedenle cumartesi, kahvaltı gibi iyelik ekli tamlama yapılarına yer verilmemiştir. Bu yolla Hint-Avrupa dillerinin karma sözcük yapılarının birebir modellerine uygun Türkçe sözcüklere yer verilmiş böylece Türkçenin karma sözcük yapılarını tarihsel olarak da kullandığı ve batılı dillerden örnek almadığı gösterilmeye çalışılmıştır.

5. Türkçenin tarihi ve çağdaş bütün sözlüklerinin taranmasıyla bu yapılara ilişkin daha fazla örnekle karşılaşılacağı açıktır. Bizim çalışmamızın amacı bu konuda yapılacak çalışmalara bir model oluşturmak ve bu karma yapıların ana hatlarını belirlemektir. 


\section{Kaynakça}

AKTUNÇ H. (1998). Türkçenin Büyük Argo Sözlüğü, İstanbul: YKY.

ALGEO, J. (1977). Blends, a structural and systemic view, American Speech, 52, 47-64.

AYVERDİ, İ. (2011). Misalli Büyük Türkçe Sözlük, 1-3. İstanbul: Kubbealtı.

BAKARADZE, E. K. (2010). Principle of the Least Effort: Telescopic Wordformation. International Journal of Arts and Sciences, 3(16): 86-105. Oxford.

CLAUSON, SİR G. (1972). An Etymological Dictionary Pre-Thirteenth-Century Turkish.

DOERFER, G. (1963-1975). Türkische und Mongolische Elemente im NeuPersischen. I-IV, Wiesbaden.

ERDAL, M. (1991). Old Turkic Word Formation I-II. Wiesbaden.

EREN, H. (1999). Türk Dilinin Etimolojik Sözlüğü. Ankara: TDK.

GÖZÜTOK, A. (2008). Türkiye Türkçesinde Karma Kelimeler. A.̈̈. Türkiyat Araştırmaları Enstitüsü Dergisi, Sayı 36, Erzurum.

GRIES, S. TH. (2004). Shouldn't İt be breakfunch? A quantitative analysis of blend structure in English. Linguistic, 42-3, 639-667.

GÜLENSOY, T. (2007). Türkiye Türkçesindeki Türkçe Sözcüklerin Köken Bilgisi Sözlüğü, I-II. Ankara: TDK Yay.

Lİ, Y. S. (1999). Türk Dillerinde Akrabalık Adları. İstanbul: Simurg.

NALBANT, M. V. (2008). An Analysis of Alternation as a Means of Word Derivation in Turkish by Focusing on Dịvānu Lugāati't-Turk. International Journal of Central Asian Studies, Volume 12. Helsinki.

RÄSÄNEN, M. (1969). Versuch Eines Etymologischen Wörterbuchs der Türksprachen.

SARI, M. (2008). Türkçenin Batı Dilleriyle İlişkisi. Ankara: TDK Yay.

TEKIN, T. (1960). Amca ve Teyze Kelimeleri Hakkında. TDAY-Belleten, s. 283-294.

TEKIN, T. (2003). Zetacism and Sigmatism in Proto-Turkic. Makaleler I. Ankara: Grafiker Yay.

TIETZE, A. (2002). Tarihi ve Etimolojik Türkiye Türkçesi Lugatı 1, A-E. İstanbul-Wien: Simurg.

TIETZE, A. (2009). Tarihi ve Etimolojik Türkiye Türkçesi Lugatı, Cilt 2, F-J. Wien.

Türkçe Sözlük (2005). Ankara: TDK.

YUDAHİN, K.K. (1994). Kırgız Sözlüğ̈̈ I-II. (Çev.: Abdullah Taymas). Ankara: TDK Yay.

BLEND, http://en.wikipedia.org/wiki/Blend:20.10.2012

FAUCONNIER G; TURNER M. (1996), "Blending as a Central Process of Grammar", http://www.cogsci.ucsd.edu/ faucon/BEIJING/blending-grammar.pdf, 12.10.2012.

Hadi Bey Hadi (2010), Arın Türkçe Etimoloji Sözlük, www.Turuz.net

KAZMAZ, S. (2012), http://www.turkishcuisine.org/pages.php?ParentID=5\&FirstLevel=71, 16.10. 2012

Avrasya, tdkterim.gov.tr/bts/, 12.10.2012 